\title{
EMDR's Efficacy for Obsessive Compulsive Disorder
}

\author{
Karsten Rüdiger Böhm \\ Department of Psychiatry and Psychosomatics, Privatklinik Friedenweiler, Germany
}

\begin{abstract}
This article evaluates eye movement desensitization and reprocessing (EMDR) therapy for individuals with a diagnosis of obsessive compulsive disorder (OCD). Two randomized controlled trials (RCTs) have been conducted on 55 and 90 patients with OCD. One RCT showed that EMDR was superior to citalapram in reducing OCD symptoms, and the other found EMDR treatment and exposure and response prevention equally effective in decreasing symptoms, with results maintained at 6-month follow-up. In addition to examining these RCTs, this article looks at several case studies to discuss three types of EMDR treatment targets (past, present, and future), and the integration of EMDR therapy with cognitive behavioral strategies such as in vivo exposure. Future research is needed before any definitive conclusions can be made.
\end{abstract}

Keywords: obsessive compulsive disorder; OCD; EMDR; exposure; behavioral strategies

0 bsessive compulsive disorder (OCD) is defined in the Diagnostic and Statistical Manual of Mental Disorders, Fifth Edition (DSM-5) as characterized by obsessions, which are "recurrent and persistent thoughts, urges, or images that are experienced as intrusive and unwanted," and/or by compulsions, which are "repetitive behaviors or mental acts that an individual feels driven to perform in response to the obsession or according to (rigid) rules" (American Psychiatric Association [APA], 2013, p. 235). OCD is difficult to treat and tends to show a high risk of chronification. The current prevalence of OCD is $1 \%-$ $3 \%$. It occurs worldwide without apparent cultural differences in prevalences, where just the content of the obsessions differs between cultures (Hohagen, WahlKordon, Lotz-Rambaldi, \& Muche-Borowski, 2015; National Collaborating Centre for Mental Health, 2006).

The functional consequence of an OCD differs between patients, but a dysregulation of negative emotions and experiences seems to be ubiquitous. Many patients report reduced quality of life, with social and occupational impairments (APA, 2013). Substantial amounts of time can be spent on the obsessions and compulsions, and related avoidance behaviors can result in restricted activities. Also associated are developmental difficulties and familial stress.

Traumatic events can be related to the onset of OCD, but there is no evidence that trauma is a prerequisite for its development (Maier, Kuelz, \& Voderholzer, 2009). An interaction between life events and genes is focused in the Diathesis-Stress Model (Cromer, Schmidt, \& Murphy, 2007). The DSM-IV (APA, 1994) and International Classification of Diseases, 10th Revision (Dilling, Mombour, \& Schmidt, 2005) describe OCD as a form of anxiety disorder, where other models postulate multifunctional genesis.

In OCD treatment, therapy focuses on four perspectives:

1. The obsession as an intrusive thought

2. The core-belief related to the obsession that makes it so dangerous or unbearable

3. Negative emotions such as fear, disgust, and related shame

4. The compulsions and avoidance, which are used to deal with the overwhelming distress.

Exposure and response prevention (ERP) and cognitive therapy are recommended in many RCTs and 
treatment guidelines worldwide for OCD treatment (NICE, 2006). Therefore, cognitive behavioral therapy (CBT) treatment is currently seen as the most efficient. Yet, many studies report a high number of dropouts (e.g., 28\% in Foa, Yedin, \& Lichner, 2005).

Eye movement desensitization and reprocessing (EMDR) therapy is recognized as an efficacious treatment for posttraumatic stress and disturbing memories. It is now being provided to individuals presenting with a range of other disorders (Valiente-Gomez et al., 2017). Although it has been found effective in the treatment of OCD, research in this area is very preliminary.

This article is a brief narrative review. Its purpose is to examine EMDR therapy's efficacy for the OCD population. Inclusion criteria for the review were randomized controlled trials (RCTs) that investigated EMDR treatment of diagnosed OCD. Searching for RCTs in that specific area, literature databases were used, including Cochrane database. Two published RCTs using EMDR in OCD patients were found and included in the review. Both controlled studies are not included in treatment guidelines up to this point. The article also discusses clinical practice, examining case studies to understand the types of treatment targets and the integration of EMDR and CBT.

\section{EMDR Treatment of OCD}

\section{Treatment Conceptualization}

The diathesis-stress model for OCD patients (Cromer et al., 2007) suggests that therapeutic work on critical life events such as traumas might be helpful for OCD treatments (Gershuny et al., 2007). EMDR therapy is based on the adaptive information processing (AIP) model (Shapiro, 2018), which views most pathology as a symptom of unprocessed distressing memories. It posits that when these memories are processed with EMDR therapy, the disturbance resolves, and the disorder remits. Although current research shows a heterogeneous picture for the genesis of OCD (Maier et al., 2009), traumas and minor traumatization in OCD could be understood in the AIP model, viewing obsessions as stored and stuck in the brain's neural network. Any memory of an OCD obsession or compulsion can cause the person to connect to the negative feelings and cognition associated with it.

\section{Choice of Targets}

EMDR therapy uses a three-pronged protocol, addressing past, present, and future aspects of the presenting problem. Standard EMDR therapy typically starts with processing the past events, which are assumed to have precipitated the disorder. This is followed by addressing current triggers and creating templates for future desired events. However in OCD treatment, different protocols use different starting points.

Past. Some studies have used EMDR's standard trauma-focused procedure, identifying and processing earlier traumatic events that appeared related to the onset of OCD. Good results were reported in case studies (e.g., Keenan, Farrell, Keenan, \& Ingham, 2018) and in an RCT (Nazari, Momeni, Jariani, \& Tarrahi, 2011).

Present. Marr (2012) views OCD as selfperpetuating and posited that the OCD is "maintained by current thoughts and behaviors" (p. 6). His protocol targets "each current trigger-each obsession and compulsion - ... as a separate recent 'traumatic event'” (p. 11) prior to targeting historical traumatic events. Support for Marr's protocol is found in his case study with treatment refractory patients (2012) and in an RCT (Marsden, Lovell, Blore, Ali, \& Delgadillo, 2017).

Future. In their case study with treatment refractory clients, Keenan et al. (2018) used the flashforward inverted protocol (Logie \& De Jongh, 2015) for patients unable to identify historical events to address possible "intolerance of uncertainty" (Wheaton, Abramowitz, Jacoby, Zwerling, \& Rodriguez, 2016). The target is the most disturbing future imaginable when obsessions are interfering in daily functioning. For example, an OCD patient might expect God would punish her/ him for failing to complete a compulsive behavior. Their case study showed some preliminary support for this application.

\section{Integration With CBT}

Several case studies have described good outcomes from combining EMDR with ERP or CBT treatment patients (e.g., Böhm \& Voderholzer, 2010; Mazzoni, Pozza, La Mela, \& Fernandez, 2017). One advantage of this combination is that in vivo triggering may allow better access to the memory network during EMDR's phase 3 (Böhm \& Voderholzer, 2010). For example, the client touches the floor ("confrontation with dirt"), then touches his/her arm ("feeling dirty"), and concentrates on that feeling, to effectively start phase 3 in EMDR. Other CBT strategies such as symptom monitoring, functional analysis, and ERP were found to enhance EMDR treatment in Mazzoni's case study with treatment refractory participants. 


\section{Randomized Controlled Trials}

In 2011 Nazari and colleagues published the first RCT on the EMDR treatment of OCD and reported that the EMDR standard protocol showed a significantly better outcome than treatment with citalopram, one of the most used and efficient medications in OCD (Nazari et al., 2011). Ninety participants were randomly assigned to receive 12 sessions of EMDR or 12 weeks of citalopram treatment, $20 \mathrm{mg}$ daily. Both treatments significantly reduced OCD symptoms measured on the Yale-Brown Obsessive Compulsive Scale (Y-BOCS), and EMDR was significantly superior to the citalopram control group. The EMDR treatment was described as following standard procedures, and so it appears that they focused on traumatic events, but the article unfortunately did not include any details. Limitations of the study include a low dose (nonclinical level) of citalopram and lack of follow-up. This study had high dropout rates: $36 \%$ in the EMDR group and $30 \%$ in the citalopram group did not complete treatment.

The second RCT was published in 2017 by Marsden and colleagues, comparing Marr's (2012) "adapted EMDR for OCD" treatment intervention with Foa et al.'s (2012) ERP procedure (Table 1). Both treatments were standardized to 16 session protocols and provided to 55 participants diagnosed with OCD. There were 12 therapists, each trained in their specific method, who had experience working with OCD patients prior to the trial. All therapists had access to a group supervision and case discussions. Both the ERP and EMDR treatment groups demonstrated significantly reduced OCD symptoms immediately after treatment, as well as 6 months later, with no statistically significant difference found between treatments. The dropout rate for EMDR therapy was
$34.5 \%$ and for ERP it was $26.9 \%$, with no significant difference between groups. In addition, anxiety levels during early treatment sessions were statistically the same in both treatment groups. The findings challenge the common belief that ERP is not well tolerated, creates severe anxiety, and results in high dropouts. It also indicates that EMDR therapy is as effective as ERP, the gold standard treatment for OCD.

\section{Recommendations}

In summary, preliminary research indicates that EMDR treatment in OCD patients may be effective. More RCTs with sufficient sample sizes are necessary to support these findings. It is also very important that the exact use of EMDR is described in detail, especially identifying the types of targets used in treatment. Research should continue to compare EMDR therapy with gold standard treatments such as ERP. It should further explore the integration of EMDR therapy with CBT components, such as Böhm's in vivo triggering of OCD symptoms.

Clinicians working with patients with OCD need flexibility with this complex presentation. They should consider the type of target most suited to the client's presentation-past trauma, current symptoms, or future fears-and whether the client might benefit from one of the adapted protocols. They might also consider the advantages of incorporating some CBT elements into their treatment practice.

\section{References}

American Psychiatric Association. (1994). Diagnostic and statistical manual of mental disorders (4th ed.). Washington, DC: Author.

TABLE 1. Characteristics of the Randomized Controlled Studies for Patients With OCD

\begin{tabular}{|c|c|c|c|c|c|}
\hline Study & Treatments & Targets & $N(\mathrm{f} / \mathrm{m})$ & No. of Sessions & Findings \\
\hline $\begin{array}{l}\text { Nazari } \\
\text { et al. (2011) }\end{array}$ & $\begin{array}{l}\text { Standard EMDR } \\
\text { versus citalopram, } \\
20 \mathrm{mg} \text { daily, }\end{array}$ & $\begin{array}{l}\text { Trauma (not } \\
\text { described in detail) }\end{array}$ & $60(33 / 27)$ & $\begin{array}{l}12 \text { sessions } \\
(60 \text { minutes), over } \\
12 \text { weeks }\end{array}$ & $\begin{array}{l}\text { Both EMDR and } \\
\text { citalopram significantly } \\
\text { reduced OCD symptoms; } \\
\text { EMDR significantly } \\
\text { superior to citalopram }\end{array}$ \\
\hline $\begin{array}{l}\text { Marsden } \\
\text { et al. } \\
(2017)\end{array}$ & $\begin{array}{l}\text { Marr's (2012) } \\
\text { Adapted EMDR } \\
\text { protocol versus } \\
\text { Foa's ERP }\end{array}$ & $\begin{array}{l}\text { Triggers } \\
\text { (compulsions/ } \\
\text { obsessions) }\end{array}$ & $55(34 / 21)$ & $\begin{array}{l}16 \text { sessions } \\
(60 \text { minutes }) \text {, over } \\
12 \text { weeks }\end{array}$ & $\begin{array}{l}\text { Adapted EMDR = ERP at } \\
\text { post-treatment and follow- } \\
\text { up, and for drop-out rates }\end{array}$ \\
\hline
\end{tabular}

Note. ERP $=$ exposure response prevention; $\mathrm{OCD}=$ obsessive compulsive disorder. 
American Psychiatric Association. (2013). Diagnostic and statistical manual of mental disorders (5th ed.). Washington, DC: Author.

Böhm, K., \& Volderholzer, U. (2010). Use of EMDR in the treatment of obsessive-compulsive disorder: A case series. Verhaltenstherapie, 20, 175-181. doi:10.1159/000319439

Cromer, K. R., Schmidt, N. B., \& Murphy, D. L. (2007b). An investigation of traumatic life events and obsessivecompulsive disorder. Behaviour Research and Therapy, 45, 1683-1691. doi:10.1016/j.brat.2006.08.018

Dilling, H., Mombour, W., \& Schmidt, M. H. (2005). Internationale klassifi kation psychischer störungen. ICD-10 Kapitel $V(F)$ (5th ed.). Bern: Huber.

Foa, E. B., Yedin, E., \& Lichner, T. K. (2012). Exposure and response (ritual) prevention for obsessive compulsive disorder. New York, NY: Oxford University Press.

Gershuny, B. S., Baer, L., Parker, H., Gentes, E. L., Infield, A. L., \& Jenike, M. A. (2007, February 22). Trauma and posttraumatic stress disorder in treatment-resistant obsessive-compulsive disorder. Depression and Anxiety. Advance online publication. doi:10.1002/ da.20284

Hohagen, F., Wahl-Kordon, A., Lotz-Rambaldi, W., \& Muche-Borowski, C. (Eds.). (2015). S3-Leitlinie zwangs störungen [S3 guideline obsessive-compulsive disorder]. Heidelberg: Springer.

Keenan, P., Farrell, D., Keenan, L., \& Ingham, C. (2018, November). Treating obsessive compulsive disorder (OCD) using eye movement desensitisation and reprocessing (EMDR) therapy: An ethno-phenomenological case series. International Journal of Psychotherapy, 22(3), 74-91.

Logie, R., \& De Jongh, A. (2016). The flashforward procedure. In M. Luber (Ed.), Eye movement desensitisation and reprocessing (EMDR) scripted protocols and summery sheets: Treating trauma, anxiety and mood-related conditions (pp. 81-90). New York, NY: Springer Publishing.

Maier, S., Kuelz, A. K., \& Voderholzer, U. (2009). Traumatisierung und dissoziationsneigung bei zwangserkrankten: Ein Überblick. Verhaltenstherapie, 19(4), 219-227. doi:10.1159/000247333

Marr, J. (2012). EMDR treatment of obsessive-compulsive disorder: Preliminary research. Journal of EMDR Practice and Research, 6, 2-15. doi:10.1891/1933-3196.6.1.2
Marsden, Z., Lovell, K., Blore, D., Ali, S., \& Delgadillo, J. (2017). A randomized controlled trial comparing EMDR and CBT for obsessive-compulsive disorder. Clinical Psychology Psychotherapy 25(1), e10-e18. doi: 10.1002 / cpp. 2120

Mazzoni, G. P., Pozza, A., La Mela, C., \& Fernandez, I. (2017). CBT combined with EMDR for resistant refractory obsessive-compulsive disorder: Report of three cases. Clinical Neuropsychiatry, 14(5), 345-356.

National Collaborating Centre for Mental Health. (2006). Obsessive-compulsive disorder: Core interventions in the treatment of obsessive-compulsive disorder and body dysmorphic disorder. Leicester, UK: British Psychological Society.

Nazari, H., Momeni, N., Jariani, M., \& Tarrahi, M. J. (2011). Comparison of eye movement desensitization and reprocessing with citalopram in treatment of obsessive-compulsive disorder. International Journal of Psychiatry in Clinical Practice, 15, 270-274. doi:10.3109/13651501.2011.590210

Shapiro, F. (2018). Eye movement desensitization and reprocessing (EMDR) therapy: Basic principles, protocols, and procedures (3rd ed.). New York, NY: Guilford Press.

Valiente-Gomez, A., Moreno-Alcázar, A., Treen, D., Cedrón, C., Pérez, V., \& Amann, B. L. (2017). EMDR beyond PTSD: A systematic literature review. Frontiers in Psychology, 26(8), 1668. doi:10.3389/fpsyg.2017.01668

Wheaton, M. G., Abramowitz, J. S., Jacoby, R. J., Zwerling, J., \& Rodriguez, C. I. (2016). An investigation of the role of intolerance of uncertainty in hoarding symptoms. Journal of Affective Disorders, 193, 208-214. doi:10.1016/j.jad.2015.12.047

Disclosure. Karsten Böhm receives income from published books on EMDR therapy and for the training of postdoctoral professionals in this approach.

Correspondence regarding this article should be directed to Karsten Rüdiger Böhm, Department of Psychiatry and Psychosomatics, Privatklinik Friedenweiler, Germany 79877. E-mail: boehm@klinik-friedenweiler.de 